\title{
Aplication of Marketing Tools in Nonprofit Sector in Albania
}

\author{
Prof. As. Dr Xhiliola Agaraj Shehu \\ Email: xhiliola.agaraj@yahoo.com; xhiliola.agaraj@gmail.com
}

Doi:10.5901/ajis.2015.v4n3s1p97

\section{Abstract}

Nonprofit sector or third sector exists to meet those needs in society that are not met by the business sector and the public sector. The purpose of this paper is to identify the application of marketing tools by non-profit organizations operating in Albania in reaching the target audience. The hypothesis that I have raised in this paper is "There is no connection between marketing and reaching the target audience." The objectives of the research are: - Providing information on the history of the development of nonprofit organizations. - Identify the importance of using marketing tools by nonprofit organizations. - Identify the level of the use of marketing mix by NPOs operating in Albania in reaching the target audience. - Research methodology consists of using secondary and primary data. Primary data are provided through two methodological research instruments: questionnaires and in-depth interviews. The questionnaire was designed to identify the importance and the level of use of marketing tools by nonprofit organizations to reach their target audience (donors, beneficiaries, volunteers). In-depth interviews were aimed at providing more detailed information on the results of research and their interpretation. In-depth interviews were conducted after processing the questionnaire in order to argument findings by nonprofit organizations themselves. The research limitations of the study are: - Research is directed towards NPOs that under the law of NPOs are registered as associations, foundations and centers. Not included in the study, religious groups, political parties, media, or other stakeholders who are part of civil society or recognized as non-profit organizations, but are registered by a special law. - Limitations on providing quantitative data for the sector. Currently, there isn't a database on the number of NPOs that are active or inactive. Formally information can be found in the Commercial Register of the Tirana District Court and in the Tax Directory. - The study is based only on the number of NPOs that are active, according to various publications there is a difference between the registered number of NPOs and active number of NPOs. - The research involves only non-profit organizations which are Albanians. Foreign non-profit organizations that operate in Albania, has not been the object of study.

\section{Literature Review}

The purpose of the nonprofit sector is to serve society. Within the nonprofit sector, there is a variety of issues and organizations that are growing. Without the existence of profit and millions of volunteers, society would miss many valuable and diverse services and civil participation. Non-profit sector is important because it ensures services that can not be provided by the private sector. Many services needed for society don't provide benefits and are not attractive for the private sector. Private sector do not have much interest in providing such services because customers do not have the financial ability to pay for them. One important reason to study non-profit is because they are large and are growing steadily over the years, and in many countries more rapidly than the private sector. Another alternative is to evaluate of non-profit sector is in terms of employment.

Over the years there has been a noticeable increase in the number of non profit organizations, coupled with a variety of sectoral distribution. The presence of civil society in the protection of public affairs has been more evident.

Compared to previous years, NPOs cooperate more with each other, with governance structures, media and in some cases with businesses. Yet observed difficulty in building sustainable partnerships and sharing of responsibilities fairly among stakeholders, building advocacy structures, and sometimes in the dissemination of information.

Generally NPOs, especially those outside the capital of Albania, have no long-term strategies and systems to develop programs that contribute to the achievement of these strategies. Dependence of the NPO sector from foreign donors, makes it unstable institutional and limits the ability of sector to respond to the needs of their interest groups. This is one of the biggest challenges for the sustainable future of the NPO sector in Albania.

The history of the development of NPOs is divided into three phases. The first stage ends with the end of II World War, the second phase involves the communist period (1945-1990), and the third stage begins after 1991 and to date.

The idea of applying marketing to nonprofit organizations has its birth in a series of articles Philip Kotler, Sidney Levy, Gerald Zaltman, Benson Shapiro, between 1969 and 1973.

1970 and 1980 show a growth period of this philosophy and after 1980 the idea of a non-profit marketing expands 
its activities into new environments of organizations like government agencies, and new types of transactions.

There are many definitions of marketing, where for every new text published a new definition is provided. Can be examined in detail those definitions of marketing that are more popular and widely accepted. In the UK a popular definition is that given by the Marketing Institute approved by the state, that is:

Marketing is a managerial process responsible for identifying, predicting, and satisfy customer requirements in order to ensure profit.

The concept as a "process" of marketing in a marketing oriented organization begins with the definition of consumer needs and using them to provide the required product or service. A good understanding of customer needs can provide the organization more than a good design of its offer. Value can be created in any contact that the customer has with the organization. If we understand who creates value is possible to design the whole system of organization for the purpose of delivery the maximum possible value to the consumer. The definition of marketing provided by (Kotler and Fox in 1985) talks about the mechanism of value creation:

Marketing is analysis, planning, implementation and control of carefully formulated programs designed to bring the voluntary exchange of value to the target market in order to achieve organizational objectives.

Marketing aims at the design of the organization's supply to take in consideration needs and desires of the target market and the use of an effective pricing, communication and distribution to inform, motivate markets served. It is clear from the two definitions that marketing is interested in identifying and satisfying customer needs of the organization and it is clear that the staff responsible for the fulfillment of this role will be not only those who belong to the marketing department.

It what marketing can provide for a nonprofit is:

- Marketing can improve consumer satisfaction.

- Marketing can help in attracting resources to a nonprofit. Many nonprofit need to raise funds to support their work.

- Adoption of a professional marketing model can help the organization determine the distinctive competences, in other words marketing can determine what an organization can offer a society which others can't.

- A professional marketing model provides the organization with a structure within which it can work. A systematic pattern of determining the needs, objectives, plans to achieve these objectives, and a formal control of activities to ensure that objectives are being achieved minimizes losses of valuable marketing resources.

In addition to the benefits that marketing offers nonprofit organizations, there are a number of differences between the marketing application in a profitable and nonprofit organization. The following data developed by (Lovelock and Weinberg 1990) may help to explain some of the complexities of marketing functions that a nonprofit may encounter.

Many Components. In many charitable organizations there are two components while rare individuals who donate money, rare are the ones who will benefit from the services that charities will provide. In other words there is a clear distinction between withdrawal of resources and their distribution.

Non-financial objectives. Nonprofit cover a large-scale of human interests and behaviors and this is reflected in a broad range of objectives which aim.

Services and social behavior rather than physical goods. The majority of the nonprofit produce services rather than physical good

Change of the destination. The volatility of the environment in which NPOs are operating means that non-profit have little control over their destination, compared with profit businesses.

The tension between mission and consumer satisfaction. There is a tension between mission and consumer satisfaction. Current consumer satisfaction may be sacrificed by non-profits and be considered long-term benefits of society.

\section{The Results of Research and Interpretation of Findings}

From the total of sample (non-profit organizations in Albania) results that Tirana has $47.6 \%$ of sample, North of Albania $29.3 \%$ and South. $23.2 \%$. This choice is representative starting from the fact that approximately half of nonprofit organizations are concentrated in Tirana. One reason for the high percentage of NPOs in North of Albania compared with 
those at South is that priority of donors has been the northern areas through projects aimed at environmental protection, tourism development, and relations between cross boarder countries.

From the total of NPOs $51.2 \%$ are associations, $11 \%$ are foundations while the centers $37.8 \%$ of NPOs. These facts correspond with the number of NPOs registered in Tirana District Court. This is related to the fact that the associations and foundations have existed as types since 1991, while centers began to be used as designations since 2001.

If we consider the distribution of NPOs by field of activity results that $39 \%$ of NPOs operate in the field of advocacy, $36.6 \%$ of them operate in the field of social services, $24.4 \%$ in the cultural field and $24.4 \%$ in education. Organizations that operate in the environmental field are $23.2 \%$ of NPOs. Organizations that have a small percentage are those that operate in health $12.2 \%$, in business $22 \%$ and professional associations $8.5 \%$. NPOs operating in the field of advocacy are more numerous than the NPOs which operate in other areas for several reasons:

- Were the missing right at the time of the dictatorial system for which the Albanian people have more need, and this is related to the creation of the first NPOs in this field.

- Democracy in itself has human rights

- There are foreign donors who support more this field.

From the findings results that $96.3 \%$ of NPOs provide funds from foreign donors, and a very small number of their $8.5 \%$ are financed by individual donations. NPOs provide funding from other donors like the government to the extent of $41.5 \%$, here we consider like central and local government. Financed by foundations in the amount $35.4 \%$, as well as private businesses $25.6 \%$ and income from services to the extent of $25.6 \%$.

\subsection{The use of marketing mix to attract target market ( Donors, voluntares, beneficiaries)}

If we look at the type of offer, and evaluate averages conclude that it is one of the most effective tools to attract donors.

A large percentage of the NPOs think the price is used to attract donors (63.8\%) but not as much as the type of offer. To attract donor should provide a well-designed project, and just as well applicable. While price is a condition that requires the donor, in relation with the service provided which should be free, or offered at a minimum price.

$42 \%$ of NPOs claim that no matter the location to attract donors. And a small percentage of them claim that it is used. When interviewed NPOs, some of them belonging to the area of North and South claim that Tirana is favored than other districts in attracting donors.

Location is less important in attracting donors. If we look at average it is 2.2 (on a scale from 1 to 5) Table 1.

$39 \%$ of NPOs think that advertising is not used to attract donors, and $42.7 \%$ think that it has a low level of use. Reasons of such rates are:

- Advertising is expensive and NPOs are not able to cover such costs,

- The number of donors is small,

- Achievement is also small.

Table 1: Evaluation of the level of use of marketing mix tools to attract Donors

\begin{tabular}{|l|c|c|c|c|}
\hline Evaluation the use of marketing mix to attract donors & Minimum & Maximum & Mean & Std. Deviation \\
\hline Evaluation of the level of use of offer type & 1 & 5 & 4,94 &, 454 \\
\hline Evaluation of the level of use of public of price & 1 & 5 & 4,01 &, 745 \\
\hline Evaluation of the level of use of public relations & 1 & 5 & 3,96 & 1,249 \\
\hline Evaluation of the level of use of personal conviction & 1 & 5 & 3,73 &, 891 \\
\hline Evaluation of the level of use of direct marketing & 1 & 5 & 3,26 &, 457 \\
\hline Assessing the level of use of the site & 1 & 5 & 2,20 &, 686 \\
\hline Evaluation of the level of use of advertising & 1 & 5 & 1,85 &, 699 \\
\hline Evaluation of the use of sales promotion & 1 & 3 & 1,26 &, 466 \\
\hline
\end{tabular}

$79 \%$ of the NPOs surveyed think that public relations tools are used. The reasons are because these tools are seen as more reliable, more accessible to the donor, and less costly.

$75 \%$ of NPOs believe that the sales promotion is not effective to attract donors. A small percent of NPOs look as little used and focused more in exposures or fairs as a means of sales promotion.

$67 \%$ of NPOs believe that personal conviction, direct communication with donors is used in providing funds for implementation of a project. Direct communication or otherwise face to face can be more reliable convincing for the donor 
that will provide funding.

Type of the offer is very important in attracting donors in three areas taken in the study. If we look at the level of the use of marketing mix according to type of NPO we conclude that there is no difference between the use of marketing mix and type of NPO.

\section{Evaluation of the level of use of marketing mix tools to attract beneficiaries}

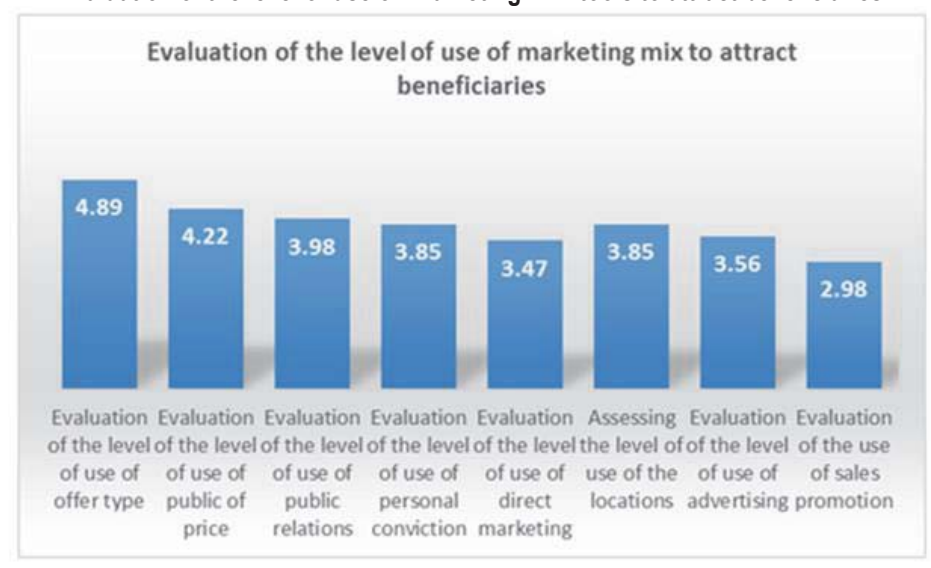

Figure 1: Evaluation of the level of use of marketing mix tools to attract beneficiaries

$96.3 \%$ of the NPOs surveyed declare that the type of the offer is used to attract the beneficiaries of service, and if you look at the averages of each of the tools of the marketing mix, type of the offer is one of the most used. But a minimum percentage think that type of the offer is not used to attract the beneficiaries. This refers to those beneficiaries that the service is associated with non-monetary costs, it may be quitting, withdrawal from drugs, fear of what others will think if someone gets the service that offers a non-profit organization.

Price is used to attracting beneficiaries and this declare $56 \%$ of NPOs, while $34 \%$ think it is very used. This relates to the fact that the service or product that offers an NPO is free or offered at a price below cost.

Location is considered as important in attracting beneficiaries, this relates not only with distance but with comfort. But some NPOs interviewed declare that it is not important in attracting beneficiaries, because depends on service that a NPO is offering.

Advertising is seen by NPOs with an average use in attracting beneficiaries, because it is very costly, although achievement may be higher, it may not be very credible or convincing.

Public relations are used to communicate with beneficiaries. They are not more expensive but more reliable.

Sales promotion tools are seen by NPOs as average used tools to attract beneficiaries. But there are a number of nonprofit organizations that think that they are not used because of the high cost associated.

Personal conviction is used to attract beneficiaries. Direct marketing is characterized by a average level of use to attract beneficiaries.

Evaluation of the efficacy of the marketing mix tools to attract volunteers.

\begin{tabular}{|l|c|c|c|c|}
\hline Evaluation of the use of marketing mix to attract volunteers & Minimum & Maximum & Mean & Std. Deviation \\
\hline Evaluation of the level of use of offer type & 1 & 5 & 4,94 &, 462 \\
\hline Evaluation of the level of use of public relations & 2 & 5 & 3,88 &, 582 \\
\hline Evaluation of the level of use of direct marketing & 1 & 5 & 3.37 & .694 \\
\hline Evaluation of the level of use of public of price & 1 & 5 & 3,34 & 1,164 \\
\hline Assessing the level of use of the location & 1 & 5 & 3,28 & 1,127 \\
\hline Evaluation of the level of use of personal conviction & 1 & 5 & 3,08 & 1,016 \\
\hline Evaluation of the level of use of advertising & 1 & 5 & 2,56 &, 793 \\
\hline Evaluation of the use of sales promotion & 1 & 4 & 2,16 &, 737 \\
\hline
\end{tabular}


Type of the offer is a very used to attract volunteers. It's the type of the offer that could matter volunteers, especially those who require a personal experience.

Public relations tools have an average level of use in attracting volunteers. They are one of the most used except the offer to providing volunteers

Location, personal conviction, and direct marketing are characterized by an average use in attracting volunteers. Location does not matter for volunteers who want to offer their services for free or at a low price. Personal conviction is moderately used because it isn't very necessary to attract volunteers because they are more interested in finding the organization.

Price has a medium level of use. $44 \%$ of NGOs believe that the price is a tool which is important in attracting volunteers in the sense that they would want to provide free time to those NPOs which offer their services for free. However, a number felt that the price does not influence the recruitment of volunteers.

Advertising and sales promotion characterized by a low level of use because they are costly, do not justify the benefits.

\section{Conclusions}

Approximately 50 percent of NPOs in the study belong to Tirana district, and the rest of the NPOs is spread across the districts. One reason is that approximately 50 percent of NPOs and exercise their activity in Tirana. North Zone has a slightly higher number of PGOs than South area. Some of the reasons are:

- NPOs in North had increased in number during the Kosovo crisis in 1999

- In recent years Northern Albania has been one of the priorities of donors for the development of tourism, environmental conservation and the creation of maintaining relations between cross border areas.

If we look at the percentage of NPOs according to type dominate associations, therefore have the highest percentage of NPOs, subsequently centers and foundations. One of the reasons is that associations and foundations have existed as a species in 1991, and centers began to be used as designations of NPOs in 2001.These figures coincide with the number of NPOs registered in Tirana District Court.

Areas of activities in which NPOs operating are, legal and political support, which is one of the areas that dominates in the NPO sector, where some of the reasons are:

- The transition from dictatorial to a democratic system require the assistance of NPOs, something which supports the creation of the first NPOs in this field.

- Community itself lacked basic rights

- This area of activity was one of the priorities of donors.

Is the field of social services which dominates the second by level of importance and involvement of NPOs in this field. Some of the reasons for the dominance of this field of activity were:

- Riots of 1997, have oriented NPOs in providing services, counseling, assistance to child, victims of trafficking and abuse.

- $\quad$ And the Kosovo crisis of 1999, which enabled the establishment of NPOs operating in the social services.

About the area in which NPOs operate are: Education and Research, Culture and Recreation, Environment, Economic and Social Development, Health, Business and Professional Associations.

Among the tools of the marketing mix which is more important in attracting donors is offering, which is connected to the idea and presenting the project. The price of the product that will be offered is important, but comes second on the scale of importance. Public relations and personal conviction are important because they more reliable and convincing. Direct marketing is characterized by average level of use, while advertising and location have a low level of use in attracting donors. Sales promotion leaflets is not used except in attracting donors.

The tools of the marketing mix used to attract beneficiaries have a different level of importance compared with the means used to attract donors. Supply and price are important for attracting beneficiaries, but used is and the location which had a low level of use to attract beneficiaries. For donors, no matter the location of the NPO, but it is important for beneficiaries in terms of distance and convenience. Sales promotion tools if some elements of it were not used at all in attracting donors have a lower use in attracting beneficiaries, this relates to the sensitivity of the market segments to marketing tools

In attracting volunteers a high level of use have the offer, because since the majority of the volunteers are students they are interested in the choice of that NPO corresponding to their field of study. Public relations are the second most important in attracting volunteers, because they more reliable and less costly. Location, direct marketing, and personal 
conviction have an average use in attracting volunteers, while advertising and sales promotion characterized by a low level of use

The use of marketing mix to attract volunteers is lower because we are dealing with a surplus of supply on their part, unless we seek a massive volunteerism.

\section{Recommendations}

Most projects of NPOs are a reflection of the priorities of donors. These priorities generally address the needs of communities in Albania. But dependence on these priorities restrains organizations to create coherent strategies and programs based on real needs identified in the community. There are NPOs that should guide donors towards the funding in those areas for which our country needs most, through the creation of institutionalized relations.

NPOs should be oriented towards alternative sources of fundraising. NPOs have the opportunity to develop activities that generate profit, but they lack the experience and capacity to manage this situation effectively.

Considering the image that non-profit sector have it is imperative by sector development of mechanisms that increase transparency in the state, in the public and other beneficiaries of its services. The first step in this direction would be the public disclosure of activity and financial situation of the NPOs.

Very encouraging and rewarding at the same time will be the use of mass media in the identification of individual donors and private businesses. Techniques that can be used, is promoting them to the beneficiaries of the service regardless of donation given, promoting them in public debates, on the Web site of organization or announcements in newspaper on donations .

Most of the NPOs operating in the field of legal assistance and social services, but are equally important and environmental and economic areas and social development. NPOs should be directed more towards these areas of activity by attracting donations from various sources in addition to providing of them by foreign donations.

The level of use of advertising in attracting donors is low except the posters who had a high level of use. Advertising should have a higher level of use in order to inform the public about services that NPOs provide, the projects they are implementing, which will aim at eliminating duplication of projects, and creating a better image to the public on the role that NPOs have in society.

Marketing tools are important in reaching the target audience, but they have a low level of use by NPOs, and themselves don't have information on marketing tools which can be used to achieve the target public. In these conditions it is necessary to provide some training courses on marketing, its importance in reaching the target market.

\section{References}

Philip Kotler, AlanR.Andreasen "Strategic marketing for nonprofit organizations". 2003 pp 442-480

Philip Kotler and Sidney J.Levy "Broadning the Concept of Marketing" 1969,pp 10-15

Philip Kotler and Gerard Zaltman, "Social Marketing" Journal of Marketig 1971, pp3-12

Philip Kotler, AlanR.Andreasen Strategic marketing for nonprofit organizations. 2003 pp 190-97

Gary J. Stern, Elona Centon "Marketing Workbook for nonprofit organizations" Volume I. Develop the plan.2001

NROGeschichte, Albania, Bonn 1997

USAID, Raport, Çështje të Zhvillimit të OJF-ve, 2002

UNESCO/ Ministria e Arsimit, Informacion Tiranë, 200

Walter Wymer, Patricia Knowles,Roger Comes "Nonprofit marketing.Marketing management for charitable and nongovermental organizations". 2006

WalterW.Wymer, N"Nonprofit and Business Sector Collaboration" 2003 pp23

Word Bank "Nongoverment Organization and Civil Society" 2001

WalterW.Wymer, N"Nonprofit and Business Sector Collaboration" 2003 pp23

Sargeant, A. Foreman, S and Kiao.M. "Operationalizing the marketing Concept in the Nonprofit sector"Journal of NPO, Vol 10, No2, 4165

Kline Henly, T. "Integrated marketing communication for local nonprofit organization: Developing an integrated marketing communication strategy:. Journal of nonprofit \& Public Sector Markeitng, 2001 pp 141-155

Lesly, P. "Lesly`s handbook of public relation and communication" (5 $5^{\text {th }}$ ed) 1998 